\begin{tabular}{|c|c|c|c|}
\hline \multirow{2}{*}{$\begin{array}{r}\text { Case Reports in } \\
\text { Gastroenterology }\end{array}$} & \multicolumn{2}{|c|}{ Case Rep Gastroenterol 2018;12:85-91 } & \multirow{3}{*}{$\begin{array}{l}\text { Karger } \\
\text { Open access }\end{array}$} \\
\hline & $\begin{array}{l}\text { DOI: } 10.1159 / 000485559 \\
\text { Publisned online: February 21, } 2018\end{array}$ & $\begin{array}{l}\text { (c) } 2018 \text { The Author(s) } \\
\text { Published by S. Karger AG, Basel } \\
\text { www.karger.com/crg }\end{array}$ & \\
\hline & $\begin{array}{l}\text { This article is licensed under the } \\
\text { International License (CC BY-NC) } \\
\text { Usage and distribution for commerci }\end{array}$ & $\begin{array}{l}\text { nons Attribution-NonCommercial } 4.0 \\
\text { ger.com/Services/OpenAccessLicense). } \\
\text { uires written permission. }\end{array}$ & \\
\hline
\end{tabular}

\title{
A Surgically Resected Pancreatic Schwannoma with Obstructive Jaundice with Special Reference to Differential Diagnosis from Other Cystic Lesions in the Pancreas
}

\author{
Takayoshi Watanabe ${ }^{a, b} \quad$ Kenichiro Araki $i^{a, b} \quad$ Norihiro Ishii ${ }^{a}$ \\ Takamichi Igarashi $^{a, b} \quad$ Akira Watanabe $^{a, b} \quad N^{a}$ Noro Kubo ${ }^{a, b}$ \\ Hiroyuki Kuwano $^{b}$ Ken Shirabe ${ }^{a, b}$ \\ ${ }^{a}$ Department of Hepatobiliary and Pancreatic Surgery, Gunma University, Graduate School \\ of Medicine, Gunma, Japan; ${ }^{b}$ Integrative Center of General Surgery, Gunma University \\ Hospital, Gunma, Japan
}

\section{Keywords}

Pancreatic schwannoma $\cdot$ Obstructive jaundice $\cdot 18$-Fluorodeoxyglucose positron emission tomography/computed tomography · Pancreatic cystic tumor

\begin{abstract}
Pancreatic schwannomas are uncommon. About $60 \%$ of pancreatic schwannomas develop cystic lesions, and the differential diagnosis from other cystic pancreatic tumors is difficult. A 43-year-old man presented for evaluation of liver dysfunction detected during a medical checkup. Blood testing detected obstructive jaundice. A computed tomography scan revealed a well-defined polycystic tumor of about $5 \mathrm{~cm}$ at the pancreatic head. We performed surgical resection to treat the patient's symptoms and facilitate long-term management. Histopathological examination revealed spindle-shaped cells. Immunohistochemical studies showed S100 protein expression and the absence of CD34 and c-kit protein expression. Finally, we diagnosed a schwannoma. Pancreatic schwannoma is usually asymptomatic. The present case presented with obstructive jaundice, which is reportedly a rare symptom. Pan-
\end{abstract}


creatic schwannomas should be considered as a differential diagnosis of pancreatic cystic tumors. Dilatation of the pancreatic duct and the 18-fluorodeoxyglucose positron emission tomography findings are important for the differential diagnosis.

(C) 2018 The Author(s)

Published by S. Karger AG, Basel

\section{Background}

Schwannomas originate from Schwann cells, which produce the myelin sheath around peripheral nerves. Schwannomas are common in cranial nerves, spinal nerves, subcutaneous tissue, and soft tissue. The development of a schwannoma in the pancreas is quite rare. Pancreatic schwannoma is usually asymptomatic. In patients with symptomatic schwannomas, abdominal pain is relatively common [1,2]. Additionally, a few cases of patients with jaundice have been reported $[3,4]$. The present case, which describes a patient with a schwannoma who presented with obstructive jaundice, is quite rare. Pancreatic schwannomas may develop both a cystic and solid lesion component. A cystic component is reportedly detected in about $60 \%$ of pancreatic schwannnomas [2], and the differential diagnosis from other cystic pancreatic tumors is difficult. We herein report a rare case of pancreatic schwannoma and differential diagnoses of cystic pancreatic lesions.

\section{Case Report}

A 43-year-old man presented for evaluation of liver dysfunction detected during a medical checkup. Laboratory data on admission to our hospital were as follows: white blood cell count, 8,900/ $\mu \mathrm{L}$; red blood cell count, $515 \times 10^{4} / \mu \mathrm{L}$; hemoglobin, $15.7 \mathrm{~g} / \mathrm{dL}$; platelets, $27.2 \times$ $104 / \mu \mathrm{L}$; total protein, $7.2 \mathrm{~g} / \mathrm{dL}$; albumin, $4.2 \mathrm{~g} / \mathrm{dL}$; total bilirubin, $9.6 \mathrm{mg} / \mathrm{dL}$; direct bilirubin, $6.8 \mathrm{mg} / \mathrm{dL}$; aspartate aminotransferase, $254 \mathrm{IU} / \mathrm{L}$; alanine aminotransferase, $584 \mathrm{IU} / \mathrm{L}$; alkaline phosphatase, 1,800 IU/L; $\gamma$-glutamyltransferase, $720 \mathrm{IU} / \mathrm{L}$; amylase, $60 \mathrm{U} / \mathrm{L}$; creatine kinase, $95 \mathrm{IU} / \mathrm{L}$; lactate dehydrogenase, $280 \mathrm{IU} / \mathrm{L}$; blood urea nitrogen, $14 \mathrm{mg} / \mathrm{dL}$; creatinine, $0.90 \mathrm{mg} / \mathrm{dL} ; \mathrm{Na}, 140 \mathrm{mEq} / \mathrm{dL} ; \mathrm{K}, 4.3 \mathrm{mEq} / \mathrm{dL} ; \mathrm{Cl}, 104 \mathrm{mEq} / \mathrm{dL}$; and C-reactive protein, 0.60 $\mathrm{mg} / \mathrm{dL}$. Blood tests revealed elevations in liver and biliary enzymes and obstructive jaundice. An abdominal enhanced computed tomography (CT) scan revealed a well-defined polycystic tumor mass $(54 \times 54 \mathrm{~mm})$ at the pancreatic head with slight enhancement of the internal septum. No metastasis to the lymph nodes or other organs was found in the CT scan (Fig. 1a). 18-Fluorodeoxyglucose positron emission tomography (FDG-PET)/CT showed a hypermetabolic appearance matching the peripheral wall of the tumor mass. The maximum standardized uptake value was 3.5 (Fig. 1b). Magnetic resonance imaging (MRI) of the abdomen revealed that the boundary of the tumor was clear and smooth. The mass exhibited high intensity on T2-weighted images. There was no continuation between the main pancreatic duct and tumor and no dilatation of the main pancreatic duct (Fig. 1c). Endoscopic ultrasound (EUS) revealed a well-defined polycystic tumor mass with an internal septum (Fig. 1d). We did not perform EUS-guided fine needle biopsy (EUS-FNAB) and cytology because the tumor mass was cystic and puncture of the mass was considered to be associated with a risk of dissemination of the cystic fluid. Preoperatively, we suspected a macro-cystic type of serous cystic neoplasm (SCN) because of the nature of the cyst, which presented in both multiple and macrocystic form. We performed endoscopic retrograde cholangiopancreatography to resolve the obstructive jaundice. We found the compression of the common bile 
duct by the tumor mass and performed endoscopic biliary drainage. The patient frequently developed cholangitis due to obstruction of the endoscopic biliary drainage tube. We considered that long-term management of this case was difficult with endoscopic treatment, and we performed subtotal stomach-preserving pancreaticoduodenectomy and modified Child reconstruction. Histopathological examination revealed spindle-shaped cells in a fasciculated and disarrayed architecture. Immunohistochemical studies showed S100 protein expression and the absence of CD34 and c-kit protein expression (Fig. 2). Finally, we diagnosed the tumor as a schwannoma. The patient had no evidence of recurrence at the time of this writing.

\section{Discussion}

$\mathrm{Xu}$ et al. [2] reviewed 68 cases of pancreatic schwannomas during the past 40 years. They found that pancreatic schwannomas developed in both men and women almost equally, usually in middle age (mean age, 55.7 years). The most common tumor location was the pancreatic head (38.2\%); others arose from the pancreatic body (20.6\%), body and tail (10.3\%), uncinate process (11.8\%), head and body (4.4\%), and tail $(11.8 \%)$. The mean tumor size was $57.5 \mathrm{~mm}$. Excluding their review, we found two case reports of pancreatic schwannoma described in the English-language literature by Ercan et al. [5] and Fukuhara et al. [6]. Xu et al. [2] found that the most common symptom of pancreatic schwannoma is abdominal pain. A few reports have described pancreatic schwannomas presenting with jaundice $[3,4]$. In the present case, the patient developed obstructive jaundice caused by compression of the common bile duct by the tumor. The tumor was located at the pancreatic head in the previous cases of patients presenting with jaundice. The present case does not conflict with previous reports in that the pancreatic head schwannoma caused jaundice.

Suzuki et al. [7] reported that the imaging characteristics of pancreatic schwannomas were correlated with the pathological features. Histologically, schwannomas usually consist of two lesions: Antoni A and Antoni B. Antoni A is characterized by spindle cells and a vascular component, while Antoni B is hypocellular and occupied by loose stroma. They reported the most common CT characteristic of pancreatic schwannoma was the presence of a lowdensity cystic lesion within the tumor. They reported that these low-density cystic images correspond to the Antoni B area or the degenerative cystic component of the schwannoma, which is unenhanced on enhanced CT scans. In contrast, an organized cellular component corresponding to the Antoni A area is well enhanced on enhanced CT scans.

EUS reveals a hypoechoic cystic pattern, which is noted in a high percentage of cases [7]. Pancreatic schwannomas exhibit both cystic and solid components. Xu et al. [2] reviewed the nature of the pancreatic schwannomas and found that the cystic type constitutes $39.7 \%$ of cases, the solid type $30.9 \%$, and the cystic and solid type $20.6 \%$. Pancreatic schwannomas with a cystic component account for almost $60 \%$ of cases. This is why the differential diagnosis from other cystic pancreatic tumors is clinically important.

The differential diagnoses of pancreatic cystic tumors might include pancreatic schwannoma, SCN, mucinous cystic neoplasm, pancreatic neuroendocrine tumor (P-NET), solid pseudopapillary neoplasm (SPN), and intraductal papillary mucinous neoplasm (IPMN) [810]. These tumors share imaging features using various modalities, and preoperative differential diagnosis of pancreatic schwannoma from the others is difficult. 
In the present case, we suspected a macrocystic-type SCN before the operation. SCN and schwannoma share imaging features such as no communication with the pancreatic duct and an oligocystic structure.

The present case also showed a hypermetabolic appearance on FDG-PET, suggesting a malignant potential. Schwannomas are usually benign tumors, but a hypermetabolic appearance on FDG-PET has been reported. Schwannomas originate from nerve cells that express glucose transporter type 3 [11], and FDG uptake is considered to be increased for this reason.

We consider that the FDG-PET findings provide useful information for the differential diagnosis. The hypermetabolic appearance of schwannomas on FDG-PET is one characteristic imaging finding, although schwannomas are usually benign tumors.

Figure 3 shows a flowchart of the differential diagnosis of pancreatic cystic lesions. First, if the tumor is accompanied by dilation of the pancreatic duct, IPMN is suspected based on the imaging findings. A malignant IPMN with mural nodules reportedly exhibits a hypermetabolic appearance on FDG-PET, corresponding to the nodules [12].

Second, the FDG-PET findings reveal useful information. According to a previous report, pancreatic benign lesions such as SCN and mucinous cystic neoplasm almost never have a hypermetabolic appearance on FDG-PET [13].

However, if FDG accumulation is positive, schwannoma must be differentiated from SPN and P-NET.

SPN and P-NET also reportedly have a hypermetabolic appearance on FDG-PET [14]. Furthermore, a recent study showed that somatostatin receptor scintigraphy may be a useful modality with which to diagnose P-NET [15].

Of course, a definitive preoperative diagnosis is not possible using only imaging modalities. The skilled use of EUS-FNAB with a plentiful specimen is still meaningful for a pathological diagnosis, although cystic lesions might be difficult to perform biopsy, as in the present case.

However, we propose that the imaging feature of dilatation of the pancreatic duct and the FDG-PET findings are useful to narrow the list of differential diagnoses of cystic pancreatic lesions as shown in the flowchart (Fig. 3). We propose consideration of pancreatic schwannoma in the differential diagnosis of pancreatic cystic tumors.

There is no specific consensus regarding the surgical treatment of pancreatic schwannoma. When we diagnose pancreatic schwannoma, simple follow-up of the patient or simple enucleation is usually considered sufficient because almost all pancreatic schwannomas are benign. The operative method varies among patients because the tumor may be present in different parts of the pancreas. A previous review of treatment by Xu et al. [2] showed that the most common type of resection was pancreaticoduodenectomy $(32.4 \%)$, while other cases involved distal pancreatectomy (26.5\%), enucleation (14.8\%), and central pancreatectomy $(1.5 \%)$.

Malignant pancreatic schwannoma is uncommon; according to the review, only 5 of 68 cases (7.4\%) were malignant [2]. Therefore, a few cases of malignant pancreatic schwannomas have been reported. Moriya et al. [1] reported a relationship among tumor size, malignant potential, and tumor nature in 47 cases of pancreatic schwannoma. The authors reported that a larger tumor size is significantly related to malignancy and cystic degeneration. They stated special attention is required for tumors of $>10 \mathrm{~cm}$ in size in terms of malignant degeneration and that oncological surgery should be considered.

In conclusion, we have herein reported quite a rare case of a pancreatic schwannoma presenting with obstructive jaundice. Obtaining a preoperative definitive diagnosis was 
quite difficult because other pancreatic cystic tumors share the same imaging features. We propose consideration of pancreatic schwannoma as a differential diagnosis of pancreatic cystic tumors. The imaging feature of dilatation of the pancreatic duct and the FDG-PET findings appear to be useful to narrow the list of differential diagnoses of cystic pancreatic lesions.

\section{Statement of Ethics}

Approval from the Ethics Committee was not required for this case report. Written informed consent was obtained from the patient for publication of this case report and any accompanying images.

\section{Disclosure Statement}

None of the authors has any financial conflicts of interest to declare.

\section{References}

1 Moriya T, Kimura W, Hirai I, Takeshita A, Tezuka K, Watanabe T, et al: Pancreatic schwannoma: case report and an updated 30-year review of the literature yielding 47 cases. World J Gastroenterol 2012;18:1538-1544.

-2 Xu SY, Wu YS, Li JH, Sun K, Hu ZH, Zheng SS, et al: Successful treatment of a pancreatic schwannoma by spleen-preserving distal pancreatectomy. World J Gastroenterol 2017;28:3744-3751.

-3 Eggermont A, Vuzevski V, Huisman M, De Jong K, Jeekel J: Solitary malignant schwannoma of the pancreas: report of a case and ultrastructural examination. J Surg Oncol 1987;36:21-25.

-4 Tofigh AM, Hashemi M, Honar BN, Solhjoo F: Rare presentation of pancreatic schwannoma: a case report. J Med Case Rep 2008;2:268.

5 Ercan M, Aziret M, Bal A, Şentürk A, Karaman K, Kahyaoğlu Z, et al: Pancreatic schwannoma: a rare case and a brief literature review. Int J Surg Case Rep 2016;22:101-104.

6 Fukuhara S, Fukuda S, Tazawa H, Imaoka K, Mochizuki T, Hirata Y, et al: A case of pancreatic schwannoma showing increased FDG uptake on PET/CT. Int J Surg Case Rep. 2017;36:161-166.

7 Suzuki S, Kaji S, Koike N, Harada N, Hayashi T, Suzuki M, et al: Pancreatic schwannoma: a case report and literature review with special reference to imaging features. JOP 2010;11:31-35.

8 Farrell JJ: Prevalence, diagnosis and management of pancreatic cystic neoplasms: current status and future directions. Gut Liver 2015;9:571-589.

-9 Brugge WR: Diagnosis and management of cystic lesions of the pancreas. J Gastrointest Oncol 2015;6:375-388.

10 Jana T, Shroff J, Bhutani MS: Pancreatic cystic neoplasms: review of current knowledge, diagnostic challenges, and management options. J Carcinog 2015;14:3.

11 Beaulieu S, Rubin B, Djang D, Conrad E, Turcotte E, Eary JF: Positron emission tomography of schwannomas: emphasizing its potential in preoperative planning. AJR Am J Roentgenol 2004;182:971-974.

-12 Tomimaru Y, Takeda Y, Tatsumi M, Kim T, Kobayashi S, Marubashi S, et al: Utility of 2-[18F] fluoro-2deoxy-D-glucose positron emission tomography in differential diagnosis of benign and malignant intraductal papillary-mucinous neoplasm of the pancreas. Oncol Rep 2010;24:613-620.

13 Sperti C, Pasquali C, Chierichetti F, Liessi G, Ferlin G, Pedrazzoli S: Value of 18-fluorodeoxyglucose positron emission tomography in the management of patients with cystic tumors of the pancreas. Ann Surg 2001;234:675-680.

14 Guan ZW, Xu BX, Wang RM, Sun L, Tian JH: Hyperaccumulation of (18)F-FDG in order to differentiate solid pseudopapillary tumors from adenocarcinomas and from neuroendocrine pancreatic tumors and review of the literature. Hell J Nucl Med 2013;16:97-102.

15 Dromain C, Déandréis D, Scoazec JY, Goere D, Ducreux M, Baudin E, et al: Imaging of neuroendocrine tumors of the pancreas. Diagn Interv Imaging 2016;97:1241-1257. 


\section{Case Reports in Gastroenterology}

\begin{tabular}{l|l}
\hline Case Rep Gastroenterol 2018;12:85-91 \\
\hline DOI: 10.1159/000485559 & $\begin{array}{l}\text { C 2018 The Author(s). Published by S. Karger AG, Basel } \\
\text { www.karger.com/crg }\end{array}$ \\
\hline
\end{tabular}

Watanabe et al: A Surgically Resected Pancreatic Schwannoma with Obstructive Jaundice with Special Reference to Differential Diagnosis from Other Cystic Lesions in the Pancreas
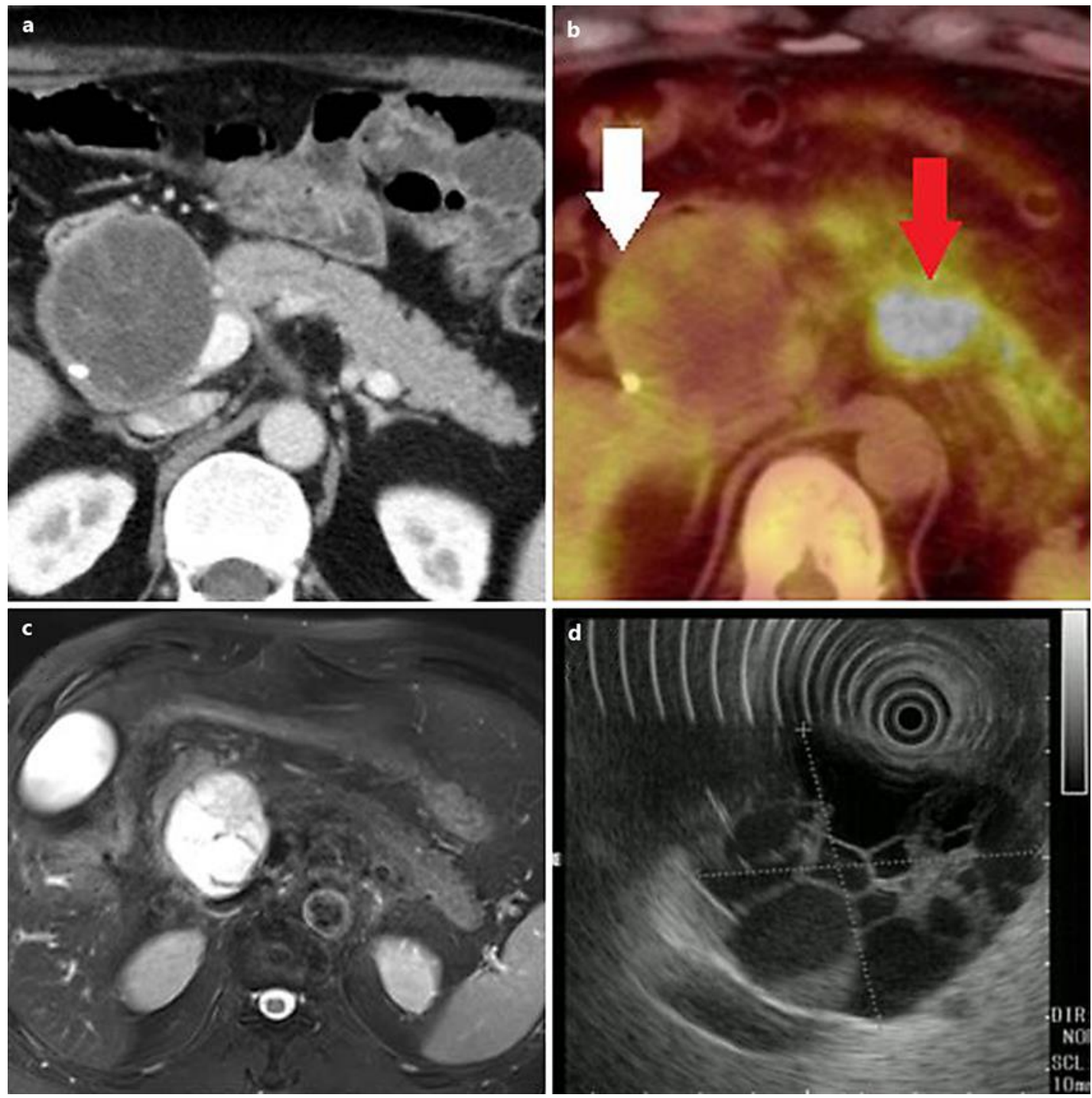

Fig. 1. Imaging findings of the tumor. a CT revealed a well-defined polycystic tumor mass at the pancreatic head. b Accumulation of fluorodeoxyglucose was demonstrated in the pancreatic head on FDG-PET. The maximum standardized uptake value was 3.5 (white arrow). A diffuse hypermetabolic appearance matching the pancreas was caused by endoscopic retrograde cholangiopancreatography-induced pancreatitis (red arrow). c MRI revealed a well-defined cystic mass exhibiting high intensity on T2-weighted images at the pancreatic head. $\mathbf{d}$ EUS revealed a well-defined hypoechoic polycystic tumor with an internal septum at the pancreatic head. 


\section{Case Reports in Gastroenterology}

Case Rep Gastroenterol 2018;12:85-91 DOI: $10.1159 / 000485559$

(C) 2018 The Author(s). Published by S. Karger AG, Basel www.karger.com/crg

Watanabe et al: A Surgically Resected Pancreatic Schwannoma with Obstructive Jaundice with Special Reference to Differential Diagnosis from Other Cystic Lesions in the Pancreas
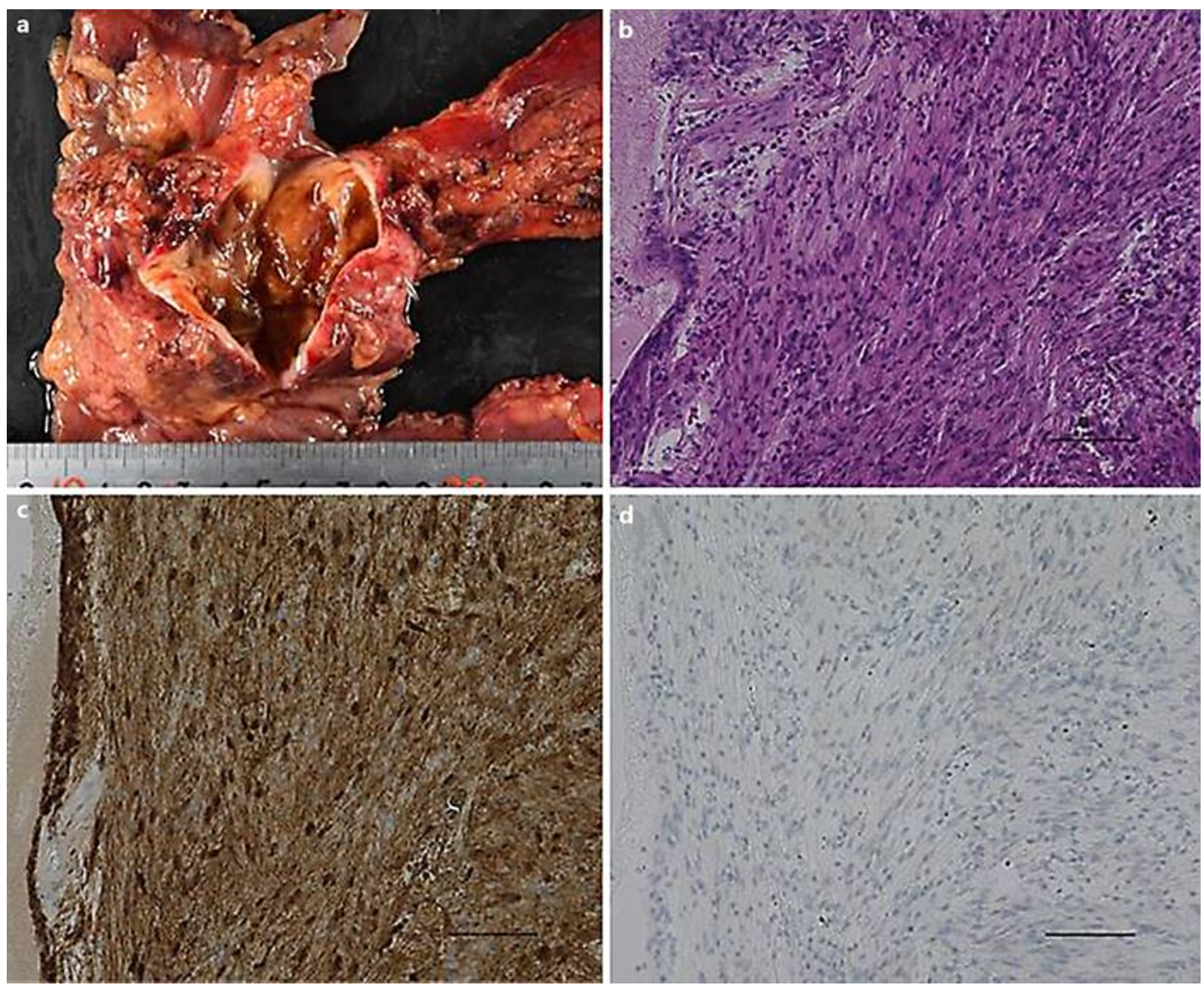

Fig. 2. Representative photomicrographs of tissue sections. a The resected specimen obtained from subtotal stomach-preserving pancreaticoduodenectomy revealed a cystic mass $(80 \times 75 \times 30 \mathrm{~mm})$ at the pancreatic head. $\mathbf{b}$ The tumor was composed of spindle-shaped cells in a fasciculated and disarrayed architecture (hematoxylin-eosin, $\times 200)$. c S-100 was detected in the tumor cells $(\times 200)$. d C-kit was not detected in the tumor cells $(\times 200)$.

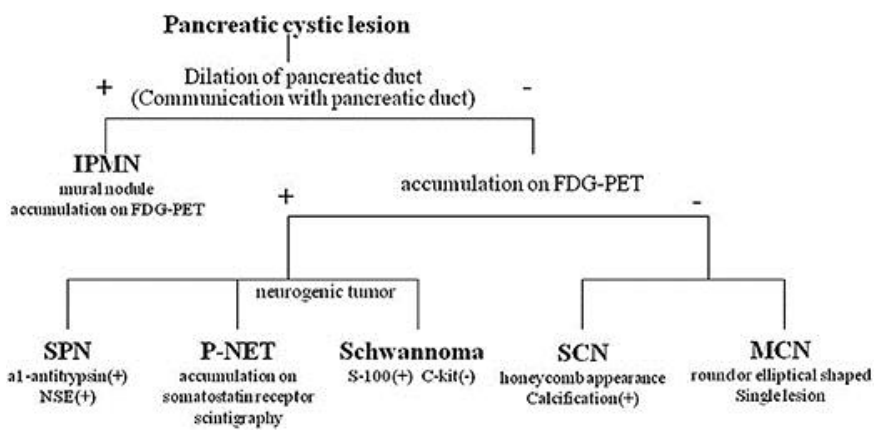

Fig. 3. Flowchart of differential diagnosis of pancreatic cystic lesions. IPMN, intraductal papillary mucinous neoplasm; FDG-PET, 18-fluorodeoxyglucose positron emission tomography; SPN, solid pseudopapillary neoplasm; NSE, neuron-specific enolase; P-NET, pancreatic neuroendocrine tumor; SCN, serous cystic neoplasm; MCN, mucinous cystic neoplasm. 